\title{
DEVELOPMENT OF BIODEGRADABILITY INDICATORS FOR MICROWAVE SLUDGE CONDITIONING
}

\author{
Author(s): \\ S. Beszédes ${ }^{1}-$ P. Veszelovszki² - L. Ludányi ${ }^{1}-$ G. Keszthelyi-Szabó1 1 - C. Hodúr ${ }^{1}$
}

Affiliation:

'Department of Process Engineering, Faculty of Engineering, University of Szeged, Moszkvai blvd. 9, Szeged, H-6725

${ }^{2}$ Technical Institute, Faculty of Engineering, University of Szeged, Moszkvai blvd. 9, Szeged, H-6725

Email address:

beszedes@mk.u-szeged.hu, veszelov@mk.u-szeged.hu, ludanyi.lajos@gmail.com, szabog@mk.u-szeged.hu, hodur@mk.u-szeged.hu

\begin{abstract}
Microwave irradiation has a good potential to increase the ability of organic matter for biological degradation. Because of the strong disintegration effect of microwave irradiation on extracellular polymeric substances (EPS), which form complex sludge structure, and also on microbial cell walls has led to enhanced solubility of organic matters, given by the ratio of soluble to total chemical oxygen demand (SCOD/TCOD). From the aspect of the further utilization of sludge, the change of biochemical oxygen demand (BOD), which correlates the degradable organic matters of sludge under aerobic condition, can be considered advantageous. For comparison purpose, and for modeling and optimization of process, it is needed to create novel control parameters, by which can be measured the changes in organic matter fraction of sludge independently from the varying characteristic or different origin of raw sludge. Based on our results, it has established that in the range of $90-1050 \mathrm{kJkg}^{-1}$, and $0.5-5 \mathrm{Wg}^{-1}$ for IMWE and MWPL, the surface fitted by constructed model can be characterized by a maximum value for BDI. Microwave treatment carried out over a certain value of MWPL and IMWE has resulted in lower biodegradability. Optimum range of IMWE and MWPL was concluded as $600-650 \mathrm{~kJ}$ and $2.5-3.0 \mathrm{Wg}^{-1}$, respectively, and both process parameters have significant effect on the change of BDI and SLI, as well.
\end{abstract}

\section{Keywords}

wastewater sludge, biodegradability, microwave pre-treatment

\section{Introduction}

Nowadays, because of the shortening of water resources, expectations for higher capacity and cleaning efficiency of wastewater purification technologies are growing. Notwithstanding of the technological development of wastewater treatment works the amount of sludge produced in these process is continuously increasing. Taking into consideration the environmental awareness and the more and more rigorous pollution control regulations, the research and development activity focuses on the sludge utilization processes. However the sludge utilization and valorization technologies require applying pre-treatments.

The sludge pre-treatment processes aim mainly the volume reduction to reduce the cost of transportation and storage, the destruction of pathogen microorganisms to decrease the microbial risk of sludge, the removal of the toxic components of sludge to reduce the environmental risk, or the enhanced degree of further utilization efficiency. Respect to the nowadays used industrial scale sludge handling technologies the thermal pre-treatments can be considered as the more commonly used processes. The advantageous effect of thermal pre-treatment on the sludge structure have been verified and utilized for decades [1]. The main aim for applying thermal pre-treatments is to reduce the odour load of sludge processing, to reduce the microbial risk of sludge disposal and to increase the organic matter removal efficiency of anaerobic digestion in industrial scale technologies

Previous investigations have been verified, that microwave irradiation is applicable in various waste and by-products handling technologies with high efficiency. Beside these advantages, it can be concluded, that the effects and efficiency of microwave processes are not enough deeply investigated and analyzed for many types of materials. It can be also established, that results of studies on microwave sludge conditioning obtained mainly from municipal sludge processing. The main advantages of microwave heating over the conventional heating methods are the following: rapid heat generation, volumetric heating, selecting heating mechanism in multicomponent system resulted from the different dielectric properties of components, and the very short process time demand due to the high energy intensity of microwave irradiation [2]. Application of MW irradiation combining with the oxidation process, such as ozonation, can also be considered to be promising technology as pre-treatment before $\mathrm{AD}$ of high organic matter containing but less degradable sludge [3].

Energy transfer carried by microwave irradiation affect the biodegradability of materials in two ways. Thermal effect is expressed in the increase of internal pressure of intracellular liquor caused by internal heating and rapid evaporation, which altogether can lead to cell wall disruption [4]. The non-thermal effect of high frequency electromagnetic field contributes to alter the structure of macromolecules with polarization of side chains and breaking of hydrogen bounds [5, 6]. High efficiency of MW treatments in the biomaterial processing and also on the rate of chemical reactions is often explained by the non-thermal effects of microwaves due to the direct interaction of electromagnetic field with molecules.

Thermal and a-thermal effects of the microwave (MW) irradiation play role in the "hot-spot” overheating phenomena, 
and the different dielectric parameter of cell components led to selective heating manifested in the different thermal stress, which contributes in the intensive degradation of cell wall components such as cellulose and pectin [7]. MW pre-treatment has verified positive effects on cell wall destruction and releasing of organic matter into the soluble phase, but combining of it with addition of chemicals such as alkali, acid and oxidizer agents cause synergetic mechanism to accelerate the decomposition under aerobic and anaerobic condition., as well [8].

Despite the good potential of microwave irradiation for material processing and the promising results of the field of microwave research the adaptation of them in industrial scale processes has been not realized yet. Available scientific results and experiences from the microwave sludge conditioning are not enough to scale up the microwave process. Furthermore, beside these advantages, it can be concluded, that the effects and efficiency of microwave processes are not deeply enough investigated and analyzed for many types of materials.

Published scientific work and research reports in the field of microwave sludge processing find microwave irradiation as an efficient method to dehydrate the sludge, and to recover some valuable component, such as some metallic compound, and microwave irradiation is suitable as pre-treatments method before anaerobic digestion to increase the biogas yield. This advantageous and beneficial feature of microwave irradiation is caused by the effect of high frequency electromagnetic field on the secondary and tertiary structure of proteins, which can manifested in the decreased stability and the enhanced disintegration degree of sludge particles [9]. It has been also concluded, that the increment in the solubility of carbohydrate compounds of sludge was approximately $10-15 \%$ higher, than the improvement in protein solubilisation after microwave treatment [10].

Comparing of the results obtained from different studies has difficulties because of the different condition of experimental setup, and the undefined or not exactly defined control parameters used for evaluation of microwave process. Therefore these observations are often led to incorrect conclusion, determined optimum parameters cannot be used for another material or equipment, and make complicated the scale up of processes. Additionally, the comparison of the efficiency of microwave operation and process parameters is difficult because the control parameters are undefined or the calculation methods are different, and the analytical methods are not standardized.

There are some studies concluded the increasing of microwave power has an increasing effect on the organic matter solubility $[10,11]$, nevertheless other studies summarized decreasing effect of the enhanced microwave power $[12,13]$. Applying microwave treatment with high power intensity in open vessel systems, the agglomeration of partly dehydrated sludge particles are observable, because of the intensive evaporation from the surface of the sludge exposed to microwave irradiation. In this case, the change in sludge structure is considered irreversible, because the water addition after the microwave treatment is not able to resolve the organic matters [14]

It can be also noticed, that results of studies on microwave sludge conditioning obtained mainly from municipal sludge processing, which has lower organic and dry matter contant than the food industry sludge. It has been established, that microwave pre-treatments of municipal sludge enhance the organic removal efficiency of anaerobic digestion process [10] and increase the biogas production [13].

\section{Materials and methods}

Investigated wastewater sludge was originated from meat industry with a total solid (TS) content of $9.7 \%$, initial total
COD of $105.9 \mathrm{kgm}^{-3}$, and soluble COD of $20.1 \mathrm{kgm}^{-3}$. Microwave experiments were carried out in a tailor made microwave sludge processing and measuring system developed at the Process Engineering Department of the University of Szeged Faculty of Engineering. Microwave equipment has a continuously irradiating magnetron with changeable power in the range of $50 \mathrm{~W}$ to $700 \mathrm{~W}$ operating at a frequency of 2450 $\mathrm{MHz}$. Power of the continuously irradiating microwave magnetron is adjustable by varying of anode voltage through a transformer with variable voltage. To investigate the efficiency of the MW pre-treatment process the parameters studied were the microwave power level (MWPL), and the irradiated microwave energy (IMWE) (Equation 1). MWPL (Wg-1) was defined as the ratio of magnetron power to the quantity of treated sludge. MWPL and IMWE were calculated from the weight of sludge samples $\left(\mathrm{m}_{\mathrm{sl}}[\mathrm{g}]\right)$, the power of magnetron $\left(\mathrm{P}_{\mathrm{m}}[\mathrm{W}]\right)$, the irradiation time $(\tau \tau[\mathrm{s}])$ and the percentage irradiation time period of magnetron (I [\%]).

$$
\text { IMWE }=\frac{P_{m} \times \tau \times I}{100 \times m_{s}} \quad\left[\mathrm{Jg}^{-1}\right]
$$

Carbonaceous biochemical oxygen demand (BOD) tests were carried out in a respirometric BOD system (BOD Oxidirect, Lovibond, Germany) thermostated at a temperature of $20 \pm 0.2^{\circ} \mathrm{C}$ (TS606, WTW). BOD analysis was according to the APHA5210D method. To ensure the consistency of the experiments, BOD seed microbe capsules (Cole Parmer, USA) were used for the measurements. The chemical oxygen demand (COD) was measured by the standardized colorimetric dichromate method using $\mathrm{HACH}$ test cuvettes, according to USEPA 5520D method. For the thermal digestion ET108 (Lovibond) thermoblock was used for 2 hours at $150^{\circ} \mathrm{C}$. The COD was measured colorimetrically using PC Checkit photometer with inner calibration for COD measurement. The total chemical oxygen demand (TCOD) was measured from the total sludge matrix. The soluble organic matter content was given as the soluble chemical oxygen demand unit (SCOD). SCOD was determined after separation of soluble from solid fraction by centrifugation (RCF of $32000 \mathrm{~g}$ for 15 minutes, MPW-350 centrifuge) and pre-filtration ( $0.45 \mathrm{\tau m}$ Millipore cellulose-acetate disc filter).

The solubility index (SLI) (Equation 2) and the biodegradation index (BDI) (Equation 3) are calculated from the total organic matter content (given by the TCOD), the soluble organic matters content (SCOD) and the biochemical oxygen demand (BOD), measuring them initially $(0)$, at a given time $(\mathrm{t})$ and from the parameters of maximum biodegradable sample (max).

$$
S L I=\frac{\left(\frac{S C O D}{T C O D}\right)_{t}-\left(\frac{S C O D}{T C O D}\right)_{0}}{\left(\frac{S C O D}{T C O D}\right)_{\max }-\left(\frac{S C O D}{T C O D}\right)_{0}} \quad[-]
$$

$$
B D I=\frac{\left(\frac{B O D}{S C O D}\right)_{t}-\left(\frac{B O D}{S C O D}\right)_{0}}{\left(\frac{B O D}{S C O D}\right)_{\max }-\left(\frac{B O D}{S C O D}\right)_{0}}[-]
$$

\section{Results and discussion}

Our earlier results verified that MW pre-treatments have numerous advantages over the conventional heating, such as higher biogas yield and accelerated anaerobic decomposition. Increment of solubility and biodegradability depend on the 
MWPL applied during microwave pretreatment and also on the irradiation time.

To analyze the effect of the two process parameters, i.e. IMWE $\left(\mathrm{x}_{1}\right)$ and MWPL $\left(\mathrm{x}_{2}\right)$, on the change of SLI and BDI response surface methodology (RSM) with CCF design was applied. Equations with significant terms remained showing that both of the factors have a linear and quadratic effect on the value of control parameters studied. Interaction among variables of IMWE and MWPL was not significant for BDI at the significance level of $0.05(\tau=\tau \%)$, but it was significant for SLI. Multiple linear regression analysis of the experimental data yielded the following second-order polynomial equation:

$S L I=0.8085+0.301 x_{1}+0.014 x_{2}+0.0706 x_{1} x_{2}-0.237 x_{1}^{2}+0.036 x_{2}^{2} \quad[-]$ $B D I=0.8921+0.071 x_{1}-0.002 x_{2}-0.298 x_{1}^{2}+0.043 x_{2}^{2} \quad[-]$

Results of the ANOVA for the quadratic model for BDI show a high degree of correlation between the predicted and observed values $\left(\mathrm{R}^{2}\right.$ value was over 0.9$)$, the lack of fit values indicated that the lack of fits were not significant relative to the pure error at a level of 0.05 . Results of RSM show that the degradation effects of MW pre-treatment were limited due to the demineralization effects. Results of response surface analysis show that MW pre-treatments enhance the SLI from 0.18 to above 0.9 at high IMWE and MWPL levels, but the increment of SLI was limited. Maximal SLI was obtained if irradiated MW energy reach IMWE value of $650 \mathrm{~kJ}$ and MW intensity was over MWPL of $2 \mathrm{Wg}^{-1}$, higher value of irradiated energy or higher intensity of MW treatment caused any further increment in the SLI (Figure 1.)

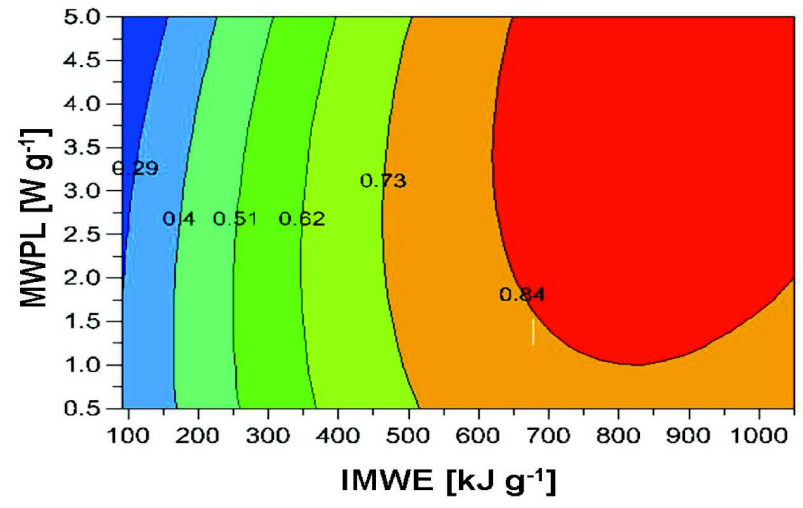

Figure 1. Contour plot for SLI

Trends of our experimental results are in good agreement with those reported by Ahn et al. [15] and Eskicioglu et al. [16], respectively; but our work was focused on the effects of different MWPL on sludge characteristic and the absolute value of differences in SLI was due to the different origin of processed sludge. Because of the strong disintegration effect of microwave irradiation on extracellular polymeric substances (EPS), which form complex sludge structure, and also on microbial cell walls has led to enhanced solubility of organic matters of food industry sludge. Degree of solubility was influenced by the preliminary treatment, increase in the absolute value of solubility was lower when secondary municipal sludge was used.

Contour plot for BDI indicate the optimum region for maximum biodegradability in IMWE range of $600-650 \mathrm{~kJ} / \mathrm{g}$, and MWPL range of 2.5-3.0 $\mathrm{Wg}^{-1}$, respectively (Figure 2). Applying IMWE and MWPL at optimum level initial BDI for untreated sludge $(0.21)$ enhanced to above 0.8 due to the microwave treatment.

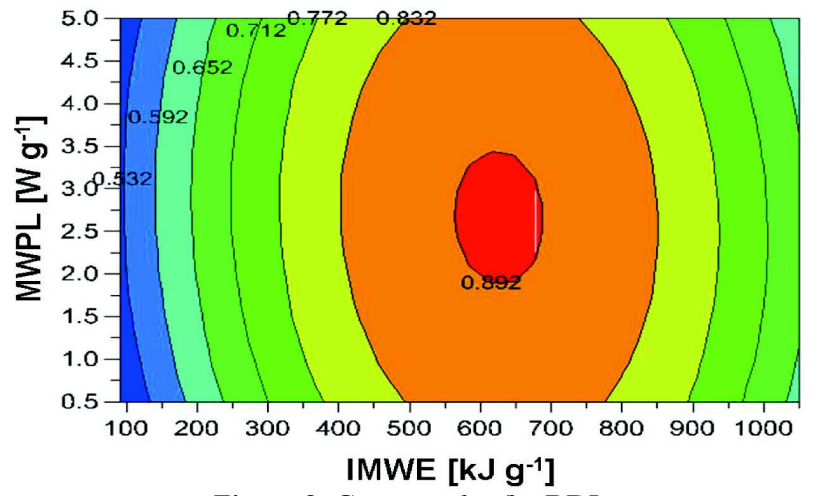

Figure 2. Contour plot for BDI

On the contrary to the results related to SLI, if the MW pretreatment was carried out with higher intensity than the optimum region, or the irradiated energy was higher than that of it, a decreasing of BDI occurred. Results of RSM show that the degradation effects of MW pre-treatment were limited due to the demineralization effects. These effects play a significant role in the worsened biodegradability after high intensity MW irradiation of high water contented sludge. Additionally, in the materials containing carbohydrates and proteins, such as the investigated sludge, Maillard reactions can be take place under high temperature treatments which can manifested in an inhibited decomposition.

\section{Conclusion}

In present work the effects of MW pre-treatments on the biodegradability of organic matters, and biogas product from meat processing wastewater sludge (MPWS) were examined. To quantify the change in the solubility of organic matter of sludge and in the degree of biodegradability the solubilization index (SLI) and the biodegradation index (BDI) were developed. Defined SLI and BDI as control parameters, effects and significance of irradiated microwave energy (IMWE) and microwave power level (MWPL) were investigated with experimental design and response surface methodology (RSM).

Our results show, that MW pre-treatments could increase the biodegradability of organic matters of MPWS. However, over a certain value of MWPL and IMWE the degree of aerobic degradation and also the biogas production was worsened. Experimental results verified, that defined solubility index (SLI) and biodegradability index (BDI) is suitable to quantify the change of physicochemical characteristics and bioavailability of organic matter fraction of sludge. Based on the results of response surface modeling (RSM) optimum region for maximum biodegradability was determined in IMWE range of of 600-650 $\mathrm{kJg}^{-1}$, and MWPL range of 2.5-3.0 $\mathrm{Wg}^{-1}$, respectively. It can be summarized, that the MW pre-treatments could be advantageous in numerous process based on biological transformation, such as activated sludge recycling processes, composting and anaerobic digestion.

\section{Acknowledgements}

This project was supported by the János Bolyai Research Scholarship of the Hungarian Academy of Sciences. The members of research group are thankful for the financial support provided by the Hungarian Scientific Research Fund (OTKA), under contract number K105021. This research was realized in the frames of TÁMOP 4.2.4. A/2-11-1-2012-0001 „National Excellence Program - Elaborating and operating an inland 
student and researcher personal support system convergence program" The project was subsidized by the European Union and co-financed by the European Social Fund.

\section{References}

[1.] Neyens E., Baeyens J.: 2003. A review of thermal sludge pre-treatment processes to improve dewaterability. Journal of Hazardous Materials B, Vol. 98, pp. 51-67. http://dx.doi.org/ 10.1016/S0304-3894(02)00320-5

[2.] Clark D .E., Folz D., West J. K.: 2000. Processing materials with microwave energy. Materials Science and Engineering A287, pp. $153-158$

[3.] Beszédes S., László Zs., Szabó G., Hodúr C.: 2009. Examination of the effect of microwave irradiation on the biodegradable and soluble fraction of organic matter of sludge. Annals of Faculty of Engineering Hunedoara-International Journal of Engineering, Vol. 7(4), pp. 87-90

[4.] Géczi G., Horváth M., Kaszab T., Alemany G. G.: 2013. No majdor differences found between the effects of microwavebased and conventional heat treatment methods on two different liquid foods. PLOS ONE Vol. 8(1), pp. 1-12 http://dx.doi.org/10.1371/journal.pone.0053720

[5.] Park B., Ahn J. H., Kim J., Hwang S.: 2004. Use of microwave pretreatment for enhanced anaerobiosis of secondary sludge. Water Science and Technology, Vol.50, pp.17-23.

[6.] Lakatos E., Kovács AJ., Neményi M.: 2005. Homogenious microwave field creation. Hungarian Agricultural Engineering, Vol. 18 , pp. $80-81$

[7.] Banik S., Bandyopadhyay S., Ganguly S.: 2003. Bioeffects of microwave-a brief review. Bioresource Technology, Vol. 87, pp. 155-159 http://dx.doi.org/10.1016/S09608524(02)00169-4

[8.] Beszédes S., László Zs., Szab, G., Hodúr C.: 2011. Effects of microwave pretreatments on the anaerobic digestion of food industrial sewage sludge. Environmental Progress and Sustainable Energy, Vol. 30, pp. 486-492 http://dx.doi.org/ 10.1002/ep.10487
[9.] Tang B., Yu L. F., Huang S. S., Luo J. Z., Zhuo Y.: 2010. Energy efficinecy of pretreating excess sewage sludge with microwave irradiation. Bioresource Technology Vol. 101(14), pp. 5092-5097. http://dx.doi.org/10.1016/j.biortech.2010.01.132

[10.] Appels L., Houtmeyers S., Dereve J., Van Impe J., Dewil R.: 2013. Influence of microwave pre-treatment on sludge solubilization and pilot scale semi-continuous anaerobic digestion. Bioresource Technology Vol. 28, pp. 598-603. http://dx.doi.org/10.1016/j.biortech.2012.11.007

[11.] Climent M., Ferrer I., Baeza M., Artola A., Vazquez F., Font F.: 2007. Effects of thermal and mechanical pretreatments of secondary sludge on biogas production under thermophilic conditions. Chemical Engineering Journal Vol. 133, pp. 335-342. http://dx.doi.org/10.1016/j.cej.2007.02.020

[12.] Park W. J., Ahn J. H., Hwang S., Lee C. K.: 2010. Effect of output power, target temperature, and solid concentration ont he solubilization of waste activated sludge using microwave irradiation. Bioresource Technology Vol. 101, pp. 13-16 http://dx.doi.org/10.1016/j.biortech.2009.02.062

[13.] Toreci I., Kennedy K, J., Droste R. L. 2009. Evaluation of continuous mesophilic anaerobic sludge digestion after high temperature microwave pretreatment. Water Resource Vol. 43, pp.1273-1284

[14.] Sólyom K., Mato R. B., Perez-Elvira S. I., Cocero M. J.: 2011. The influence of the energy absorbed from microwave pretreatment on biogas production from secondary wastewater sludge. Bioresource Technology Vol. 102(23), , pp. 10849-10854. http://dx.doi.org/10.1016/j.biortech.2011.09.052

[15.] Ahn J. H., Shin S. G., Hwang S.: 2009. Effect of microwave irradiation on the disintegration and acidogenesis of municipal secondary sludge. Chemical Engineering Journal Vol. 153, pp. 145-150. http://dx.doi.org/10.1016/j.cej.2009.06.032

[16.] Eskicioglu C., Kennedy K. J., Droste R. L.: 2006. Characterization of soluble organic matter of waste activated sludge before and after thermal pretreatment. Water Research Vol. 40, pp. 3725-3736 http://dx.doi.org/10.1016/j.watres.2006.08.017 